\title{
Fluorescein Angiographic Features, Natural Course and Treatment of Radiation Retinopathy
}

\author{
W. M. K. AMOAKU and D. B. ARCHER \\ Belfast
}

\begin{abstract}
Summary
Fifteen patients who developed retinopathy following radiotherapy for cephalic tumours were studied by fluorescein angiography. Nine patients with unilateral or bilateral retinopathy had serial angiograms at six monthly or yearly intervals. Angiography revealed a wide range of retinal microvascular changes which were graded 1-4 according to the extent and degree of capillary malformation, incompetence and closure. All patients showed slow progression of retinopathy with remodelling of the affected microvasculature and increased capillary fallout and leakage to dye.

The earliest retinopathic changes were capillary dilatation and closure and microaneurysm formation. Telangiectatic-like vessels were a feature of the established retinopathy and probably represented collateral channels which bordered sites of capillary occlusion.

Two patients with progressive macular oedema and declining vision responded favourably to focal laser photocoagulation which returned a measure of competence to some residual dilated capillaries.
\end{abstract}

The first fluorescein angiographic features of radiation retinopathy were described by Chee $^{1}$ and Gass ${ }^{2}$ who reported a microvasculopathy characterised by capillary incompetence and closure. In 1970, Hayreh ${ }^{3}$ studied three patients with choroidal melanoma treated by Cobalt 60 applicators and documented a wide range of angiographic changes in the retinal vasculature and outer retina. Bagan and Hollenhorst ${ }^{4}$ reported six cases of radiation retinopathy but angiographic changes were only described in one patient. Brown et al. ${ }^{5}$ reviewed the angiographic changes in the retinae of patients receiving external beam or plaque therapy for intraocular tumours and identified vascular occlusion as the key pathophysiological event leading to the development of radiation retinopathy.

Thompson et al. ${ }^{6}$ studied seven patients with radiation retinopathy and highlighted the value of fluorescein angiography in accurately identifying the microvascular alterations. Ehlers and $\mathrm{Kaae}^{7}$ also used fluorescein angiography to determine the extent of retinal and choroidal vaso-occlusive changes in infants receiving radiotherapy for retinoblastoma. Lommatzsch et al. ${ }^{8,9}$ and Tarkkanen and Laatikainen ${ }^{10}$ documented the regression of choroidal melanomas treated with $\mathrm{Ru}$ 106/ Rh 106 plaques using angiographic techniques. They reported the disappearance of most choroidal and retinal vessels within the irradiated area and noted that chorioretinal This research was supported by a grant from the British Council for Prevention of Blindness.

Correspondence to: Professor D. B. Archer, Eye and Ear Clinic, Royal Victoria Hospital, Grosvenor Road, Belfast BT12 6BA, Northern Ireland. 
vascular occlusion and retinal pigment epithelial atrophy continued for one year or more following irradiation.

Several authors using fluorescein angiography have commented on the inexorable nature of radiation retinopathy, ${ }^{5,6,11,12}$ although some have noted its progression may be slow. ${ }^{4}$ Natural regression of the disease process has also been reported in a few instances. ${ }^{13,14,15}$

Most studies of radiation retinopathy to this time are either case reports or single observations in small cohorts of patients receiving ocular brachytherapy or teletherapy. In most instances the disease process is advanced or end-stage and few descriptions of the early vascular changes have been available. Sequential investigations of retinopathy have been reported from time to time; ${ }^{4,6,15}$ however, the natural course of the vasculopathy, particularly the early stages, has not been studied in detail. This paper describes the fluorescein angiographic changes in the retinae of patients receiving cephalic radiation emphasising the initial vascular alterations and documenting the natural course of the disease process. The modifying effects of laser photocoagulation on the natural progression of the vasculopathy are also examined.

\section{Materials and Methods}

Fifteen patients who developed retinopathy following cephalic radiation in Northern Ireland between 1972 and 1988 were studied by fluorescein angiography. The tumour pathology, tumour sites, radiation doses and methodology are documented in Table I.

Each patient had a full assessment of visual functions, ocular biomicroscopy and fundus examination. Fluorescein angiograms were obtained with a Zeiss fundus camera following an intravenous injection of $5 \mathrm{ml}$ of $20 \%$ sodium fluorescein. High quality angiograms in one patient permitted a quantitative assessment of microvascular changes using a Kodak Image Analyser.

Nine patients with retinopathy were followed, and serial angiograms taken at six month or one year intervals. In six patients review was not possible due to advancing lens or corneal opacities or deteriorating health. The time of follow-up varied between 13 and
58.5 months, (mean follow-up time 25.8 months) (Table II).

Two patients had laser photocoagulation for progressive retinopathy and persistant macular oedema. As the affected microvasculature involved the central macula in both instances, the Argon green laser was chosen. Photocoagulation was applied to microvascular lesions, - particularly microaneurysms and telangiectatic-like capillaries and nearby retina. Areas of ischaemic and poorly perfused retina were also treated. No burns were placed within $750 \mu \mathrm{m}$ of the centre of the foveola. The first treated eye received a total of 448 burns $(100 \mu \mathrm{m} \times 0.1 \mathrm{sec} \times 0.3 \mathrm{~W})$ in two sessions. The second treated eye received 250 burns $(100 \mu \mathrm{m} \times 0.1 \mathrm{sec} \times 0.18 \mathrm{~W})$. Supplementary treatment of 181 burns $(100 \mu \mathrm{m} \times$ $0.1 \mathrm{sec} \times 0.2 \mathrm{~W})$ was given to the second patient after three months.

\section{Results}

In most patients with established radiation retinopathy angiography demonstrated striking and characteristic changes in the architecture and structure of the retinal microvasculature with varying degrees of capillary incompetence and closure. Typically, the retinopathy was concentrated in the macular and peripapillary regions; however, two patients in whom the radiation field was eccentric to the eye developed asymmetrical retinopathy corresponding to the respective fields of irradiation. One of these patients, (Case 3), a diabetic without discernible retinopathy showed widespread microaneurysms, haemorrhages and ischaemia in the irradiated superior retina of the right eye (Fig. 1). The inferior retinae displayed little or no evidence of retinopathy. The second patient (Case 15) with asymmetrical retinopathy had received radiation for a malignant melanoma of the nose and the inferior retina had been included in the radiation field. Subsequently this patient presented with extensive areas of ischaemia in the inferior retina associated with preretinal neovascularisation.

Three patients showed evidence of retinal pigment epithelial degenerative changes particularly atrophy and proliferation. A further patient who received direct orbital irradiation demonstrated a large subretinal 
Table I Radiation retinopathy-a fluorescein angiographic study

\begin{tabular}{|c|c|c|c|c|c|c|c|c|}
\hline $\begin{array}{l}\text { Case } \\
\text { No. }\end{array}$ & Patient & Eye & Tumour site & $\begin{array}{l}\text { Radiation, } \\
\text { dose } \\
\text { fractionation }\end{array}$ & Date & Chemotherapy & $\begin{array}{c}\text { Systemic } \\
\text { disease }\end{array}$ & $\begin{array}{l}\text { Angiography } \\
\text { initial date }\end{array}$ \\
\hline 1 & A.C. & $\mathrm{R}$ & Nasopharynx & $5250 \mathrm{cGy} / 25 \mathrm{f}$ & Sept 1981 & & & 23.9 .86 \\
\hline 2 & B.C. & $\begin{array}{l}\mathrm{R} \\
\mathrm{L}\end{array}$ & $\begin{array}{l}\text { (L) Nose and } \\
\text { Ethmoid }\end{array}$ & $5000 \mathrm{cGy} / 25 \mathrm{f}$ & Jan 1984 & & & $\begin{array}{c}7.5 .85 \\
29.1 .87\end{array}$ \\
\hline 3 & E.D. & $\begin{array}{l}\mathrm{R} \\
\mathrm{L}\end{array}$ & $\begin{array}{l}\text { (L) Parieto- } \\
\text { temporal } \\
\text { lobe }\end{array}$ & $4000 \mathrm{cGy} / 30 \mathrm{f}$ & Nov 1984 & $\mathrm{CCNU}^{*}$ & $\begin{array}{l}\text { Diabetes } \\
\text { mellitus } 1979\end{array}$ & 11.10 .86 \\
\hline 4 & H.D. & $\mathrm{L}$ & $\begin{array}{l}\text { (L) Lacrimal } \\
\text { sac }\end{array}$ & $2750 \mathrm{cGy} / 20 \mathrm{f}$ & Aug 1983 & $\begin{array}{l}\text { Vincristine, } \\
\text { Cyclophosphamide, } \\
\text { 5-FU† }\end{array}$ & & 9.5 .88 \\
\hline 5 & A.H. & $\mathrm{R}$ & (R) Orbit & $3350 \mathrm{cGy} / 15 \mathrm{f}$ & Jan 1972 & & & 26.3 .87 \\
\hline 6 & D.H. & $\mathbf{R}$ & (R) Orbit & $4800 \mathrm{cGy} / 20 \mathrm{f}$ & Dec 1978 & $\begin{array}{l}\text { Actinomycin D } \\
\text { Vincristine, Cyclo- } \\
\text { phosphamide }\end{array}$ & & 17.10 .88 \\
\hline 7 & S.J. & $\begin{array}{l}\mathrm{R} \\
\mathrm{L}\end{array}$ & Nasopharynx & $5000 \mathrm{cGy} / 25 \mathrm{f}$ & March 1978 & & & $\begin{array}{l}27.5 .86 \\
27.5 .86\end{array}$ \\
\hline 8 & H.K. & $\mathrm{L}$ & (L) Orbit & 3417 cGy/15f & Nov 1981 & & & 27.4 .88 \\
\hline 9 & H.M. & $\mathrm{R}$ & $\begin{array}{l}\text { (R) Maxillary } \\
\text { antrum } \\
\text { Ethmoid }\end{array}$ & 4350 cGy/20f & Oct 1977 & & & 3.6 .86 \\
\hline 10 & J.M. & $\mathrm{R}$ & (R) Orbit & $3500 \mathrm{cGy} / 19 \mathrm{f}$ & Jan 1981 & & $\begin{array}{l}\text { Diabetes } \\
\text { mellitus } 1987\end{array}$ & 28.4 .88 \\
\hline 11 & A.M. & $\begin{array}{l}\mathrm{R} \\
\mathrm{L}\end{array}$ & Nasopharynx & $5250 \mathrm{cGy} / 25 \mathrm{f}$ & Feb 1978 & & & $\begin{array}{l}6.1 .87 \\
6.1 .87\end{array}$ \\
\hline 12 & N.O. & $\begin{array}{l}\mathrm{L} \\
\mathrm{R}\end{array}$ & $\begin{array}{l}\text { (L)Lacrimal } \\
\text { sac }\end{array}$ & $\begin{array}{l}5500 \mathrm{cGy} / 25 \mathrm{f} \\
2400 \mathrm{cGy} / 25 \mathrm{f}\end{array}$ & Feb 1988 & & $\begin{array}{l}\text { Diabetes } \\
\text { mellitus } 1987\end{array}$ & $\begin{array}{l}7.12 .87 \\
7.12 .88\end{array}$ \\
\hline 13 & J.O. & $\begin{array}{l}\mathrm{R} \\
\mathrm{L}\end{array}$ & Nasopharynx & 4424 cGy/24f & Oct 1983 & $5 \mathrm{FU} \dagger$ & $\begin{array}{l}\text { Diabetes } \\
\text { mellitus } 1982\end{array}$ & $\begin{array}{l}30.6 .86 \\
30.6 .86\end{array}$ \\
\hline 14 & M.S. & $\mathrm{L}$ & $\begin{array}{l}\text { (L) Maxillary } \\
\text { antrum }\end{array}$ & $5460 \mathrm{cGy} / 26 f$ & Nov 1979 & & & 6.1 .87 \\
\hline 15 & A.T. & $\mathrm{L}$ & (L) Nose & $5000 \mathrm{cGy} / 25 \mathrm{f}$ & Jan 1981 & $\begin{array}{l}\text { Tamoxifen (for } \\
\text { breast } \mathrm{Ca} \text { ) }\end{array}$ & & 24.6 .86 \\
\hline
\end{tabular}

* CCNU 1-(2-Chlorethyl)-3-Cyclohexyl-1-Nitrosurea.

$\uparrow$ FU 5-Fluorouracil.

neovascular membrane at the macula. Details of the angiographic findings and follow-up period for each patient are listed in Table II.

\section{Grading of angiographic changes}

All varieties of reported microvascular response to radiation were identified in this study, and 15 patients ( 20 eyes) were classified according to the degree and extent of the microvascular changes.

\section{Grade 1 Retinopathy}

Two eyes demonstrated small foci of dilated and irregular retinal capillaries in association with isolated or small clusters of microaneurysms. These eyes also showed subtle evidence of capillary closure, although there was no detectable microvascular incompetence or fluid accumulation within the retina (Fig. 2). Visual functions were good in these patients i.e. $6 / 6$ or better.

\section{Grade 2 Retinopathy}

Seven eyes showed multiple foci of dilated and telangiectatic-like capillaries and zones of capillary closure up to one optic disc area in dimension. This group also showed numerous microaneurysms and focal leakage of dye from defective capillaries in later phase angiograms (Fig. 3a, b). In some patients fluorescein leakage was associated with clinically observable retinal oedema, although cystoid macular changes were absent and visual acuity remained relatively good, i.e. $6 / 9$ or better. One patient (two eyes) in this group (Case 13) was diagnosed as suffering from 
Table II Radiation retinopathy-a fluorescein angiographic study

\begin{tabular}{|c|c|c|c|c|c|}
\hline Case No. & Eye & Initial angiographic findings & Final angiographic findings & $\begin{array}{l}\text { Follow-up } \\
\text { period }\end{array}$ & $\begin{array}{l}\text { Retinopathy } \\
\text { grade }\end{array}$ \\
\hline 1 & $\mathrm{R}$ & $\begin{array}{l}\text { Small area, irregular capillaries } 2 \\
\text { microaneurysms. Focal capillary } \\
\text { closure }\end{array}$ & $\begin{array}{l}\text { Large single microaneurysm increased } \\
\text { capillary irregularity, further capillary } \\
\text { closure }\end{array}$ & 32 months & 1 \\
\hline \multirow[t]{2}{*}{2} & $\mathrm{R}$ & $\begin{array}{l}\text { Focal capillary dilatation and closure, } \\
\text { microaneurysms and intraretinal } \\
\text { haemorrhages. Focal RPE changes }\end{array}$ & $\begin{array}{l}\text { Increased area capillary dilatation and } \\
\text { number of microaneurysms. Fusiform } \\
\text { capillary loops further capillary fallout. } \\
\text { No vascular incompetence }\end{array}$ & 31 months & 1 \\
\hline & $\mathrm{L}$ & $\begin{array}{l}\text { Focal macular and perimacular inner } \\
\text { retinal ischaemia, intraretinal } \\
\text { haemorrhage, widespead capillary } \\
\text { dilatation, distortion and } \\
\text { incompetence. Multiple } \\
\text { microaneurysms }\end{array}$ & $\begin{array}{l}\text { Incomplete reperfusion ischaemic } \\
\text { retina, absorption haemorrhage. } \\
\text { Development telangiectatic-like } \\
\text { channels. Macular oedema }\end{array}$ & 58 months & 3 \\
\hline 3 & $\mathbf{R}$ & $\begin{array}{l}\text { Widespread capillary defects IRMA, } \\
\text { microaneurysms and inner retinal } \\
\text { ischaemia superior retina. Arteriolar } \\
\text { and venular occlusion. }\end{array}$ & & & 4 \\
\hline 4 & $\mathrm{~L}$ & $\begin{array}{l}\text { Dilated irregular incompetent } \\
\text { capillaries. Microaneurysms, capillary } \\
\text { closure, RPE scar, inferior macula }\end{array}$ & $\begin{array}{l}\text { Slight increase extent capillary } \\
\text { abnormalities and microaneurysms. } \\
\text { Dye leakage and retinal staining more } \\
\text { intense }\end{array}$ & 13 months & 2 \\
\hline 5 & $\mathbf{R}$ & $\begin{array}{l}\text { Extensive inner retinal ischaemia, } \\
\text { IRMA, patent and thrombosed } \\
\text { microaneurysms. Macular RPE } \\
\text { changes, subretinal neovascularisation }\end{array}$ & & & 3 \\
\hline 6 & $\mathrm{R}$ & $\begin{array}{l}\text { Dilated, disorganised macular } \\
\text { capillaries. Microaneurysms IRMA, } \\
\text { telangiectatic-like vessels, cystoid } \\
\text { macular oedema, retinal ischaemia }\end{array}$ & & & 3 \\
\hline \multirow[t]{2}{*}{7} & $\mathrm{R}$ & $\begin{array}{l}\text { Dilated, irregular capillaries. Multiple } \\
\text { microaneurysms, capillary closure and } \\
\text { staining of defective capillary bed, } \\
\text { retinal oedema }\end{array}$ & $\begin{array}{l}\text { Further capillary closure, thrombosis } \\
\text { and formation microaneurysms } \\
\text { increased dye leakage }\end{array}$ & 37 months & 2 \\
\hline & $\mathrm{L}$ & $\begin{array}{l}\text { Scattered dilated and incompetent } \\
\text { caps, focal leakage of dye into retina. } \\
\text { Microaneurysms and focal capillary } \\
\text { closure }\end{array}$ & $\begin{array}{l}\text { Small increase in microaneurysms and } \\
\text { area of vascular staining and } \\
\text { incompetence }\end{array}$ & 38.5 months & 2 \\
\hline 8 & $\mathrm{~L}$ & $\begin{array}{l}\text { Dilated telangiectatic like capillaries, } \\
\text { microaneurysms, focal retinal } \\
\text { ischaemia }\end{array}$ & $\begin{array}{l}\text { Further closure capillary bed, } \\
\text { reperfusion of some radicals within } \\
\text { ischaemic retina }\end{array}$ & 17 months & 3 \\
\hline 9 & $\mathrm{R}$ & $\begin{array}{l}\text { Dilated, incompetent capillaries, } \\
\text { microaneurysms, choroidal vascular } \\
\text { stasis, macular oedema }\end{array}$ & & & 3 \\
\hline 10 & $\mathrm{R}$ & $\begin{array}{l}\text { Telangiectatic-like vessels, } \\
\text { microaneurysms cystoid macular } \\
\text { oedema. Retinal ischaemia. Venular } \\
\text { and arteriolar staining }\end{array}$ & $\begin{array}{l}\text { Extension of microvascular } \\
\text { abnormalities, increased capillary } \\
\text { incompetence. Some reperfusion of } \\
\text { ischaemic retina }\end{array}$ & 14 months & 3 \\
\hline \multirow[t]{2}{*}{11} & $\mathrm{R}$ & $\begin{array}{l}\text { Widespread capillary closure, IRMA's } \\
\text { and telangiectatic-like channels. } \\
\text { Irregular arterioles and venules, } \\
\text { macular oedema }\end{array}$ & $\begin{array}{l}\text { Further closure of abnormal dilated } \\
\text { capillaries, additional haemorrhages } \\
\text { and increased microvascular leakage }\end{array}$ & 28 months & 4 \\
\hline & $\mathrm{L}$ & $\begin{array}{l}\text { Dilated telangiectatic capillaries. } \\
\text { Microaneurysms, early leakage } \\
\text { capillary closure }\end{array}$ & $\begin{array}{l}\text { Additional microaneurysms increased } \\
\text { microvascular incompetence }\end{array}$ & & 2 \\
\hline \multirow[t]{2}{*}{12} & $\mathrm{~L}$ & Microaneurysms focal RPE defects & $\begin{array}{l}\text { Gross macular oedema, ischaemia, } \\
\text { staining venules and arterioles }\end{array}$ & 11 months & 4 \\
\hline & $\mathrm{R}$ & $\begin{array}{l}\text { Microaneurysms small foci, } \\
\text { incompetent, occluded vessels }\end{array}$ & $\begin{array}{l}\text { Further microaneurysms, increased } \\
\text { microvascular leakage }\end{array}$ & & 2 \\
\hline \multirow[t]{2}{*}{13} & $\mathbf{R}$ & $\begin{array}{l}\text { Moderate background diabetic } \\
\text { retinopathy. Focal capillary closure and } \\
\text { leakage }\end{array}$ & $\begin{array}{l}\text { Intensification of retinopathy, increased } \\
\text { capillary leakage }\end{array}$ & 9 months & 2 \\
\hline & $\mathrm{L}$ & Microaneurysms, capillary leakage & $\begin{array}{l}\text { Increased microaneurysms and dye } \\
\text { leakage }\end{array}$ & & 2 \\
\hline 14 & $\mathbf{R}$ & $\begin{array}{l}\text { Telangiectatic-like macular vessels, } \\
\text { microaneurysms, focal capillary closure } \\
\text { macular oedema }\end{array}$ & & & 3 \\
\hline 15 & L & $\begin{array}{l}\text { Telangiectatic-like channels, extensive } \\
\text { retinal ischaemia, preretinal } \\
\text { neovascularization }\end{array}$ & & & 4 \\
\hline
\end{tabular}

* RPE Retinal pigment epithelium.

IRMA Intraretinal microvascular abnormality. 


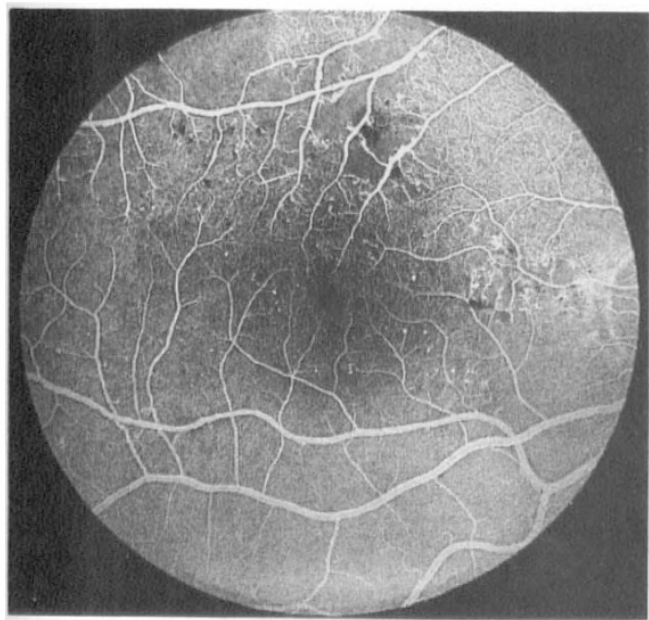

Fig. 1. Venous phase angiogram right posterior fundus, Case 3. Ischaemic retinopathy is largely confined to the irradiated superior fundus.

diabetes mellitus one year prior to receiving radiotherapy and chemotherapy for a nasopharyngeal tumour. It was not possible to determine whether the retinopathy was pri- marily due to the metabolic or radiational insult, although it is likely that it was a response to the combined or synergistic effects of radiation, chemotherapy and diabetes.

\section{Grade 3 Retinopathy}

Seven eyes in this group were characterised by widespread capillary dilatation, telangiectatic-like channels, microvascular incompetence and significant areas of capillary closure (1-4 disc areas). All patients had significant macular oedema with or without cystoid macular degenerative changes (Fig. 4). Microaneurysms and intraretinal microvascular abnormalities commonly occurred at the border of perfused and non-perfused retina. Eyes in this group typically had poor visual acuity, i.e. five eyes had vision of $6 / 18$ or worse. One patient in this group was diagnosed a diabetic six years following radiation to the right orbit (Case 10). The retinopathy was severe and unilateral and was judged to be primarily radiational in type, although the metabolic

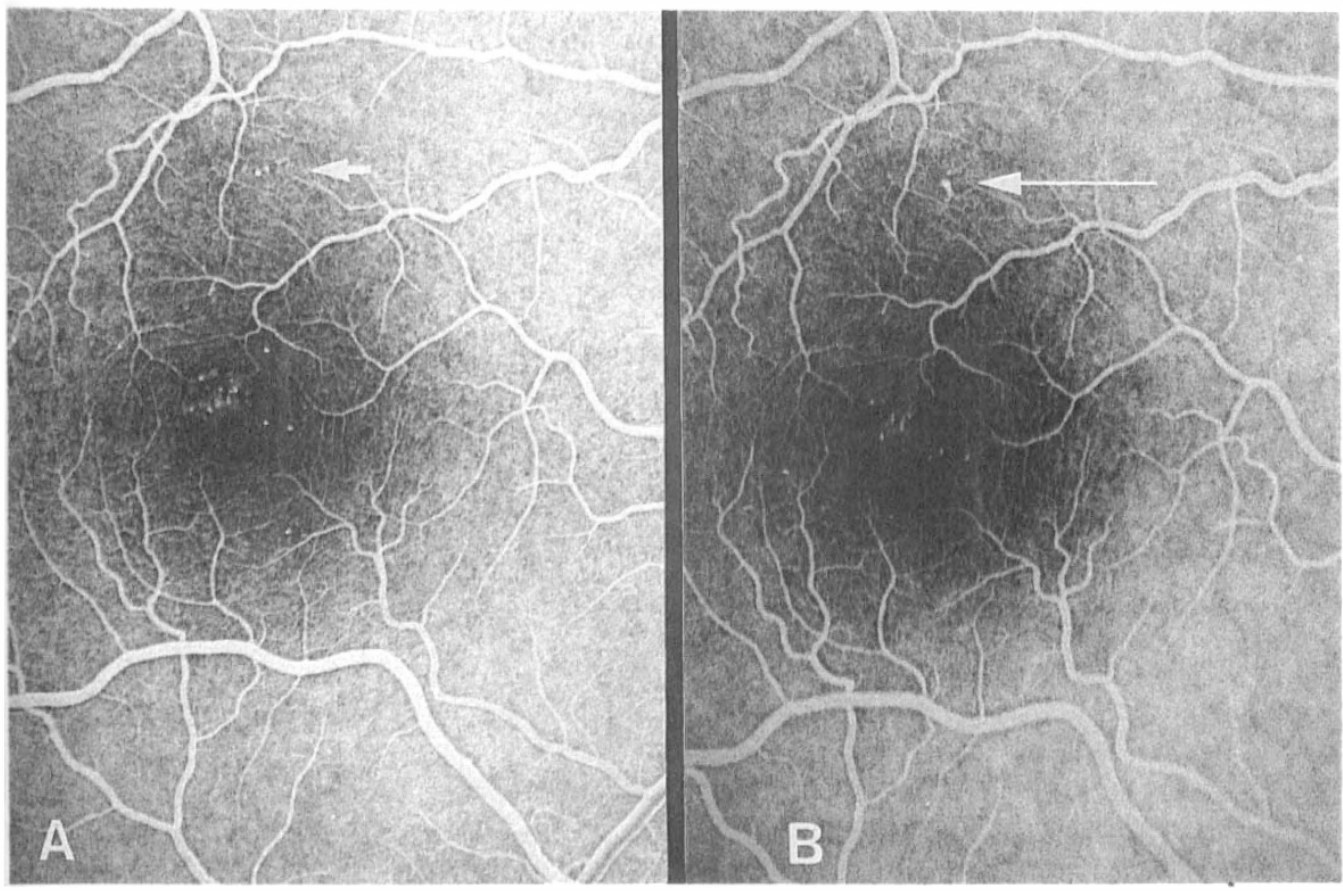

Fig. 2a. Mid-venous phase angiogram, right posterior fundus, Case 1. Capillary irregularities and microaneurysms in the superior macula (arrows) represent early radiational changes. Retinal pigment epithelial changes are present at the foveola.

Fig. 2b. Angiogram right fundus, Case 1, 32 months after that shown Fig. 2a. There is evidence of capillary fusion and closure. The wall of a dilated fusiform capillary stains with dye (arrow). 


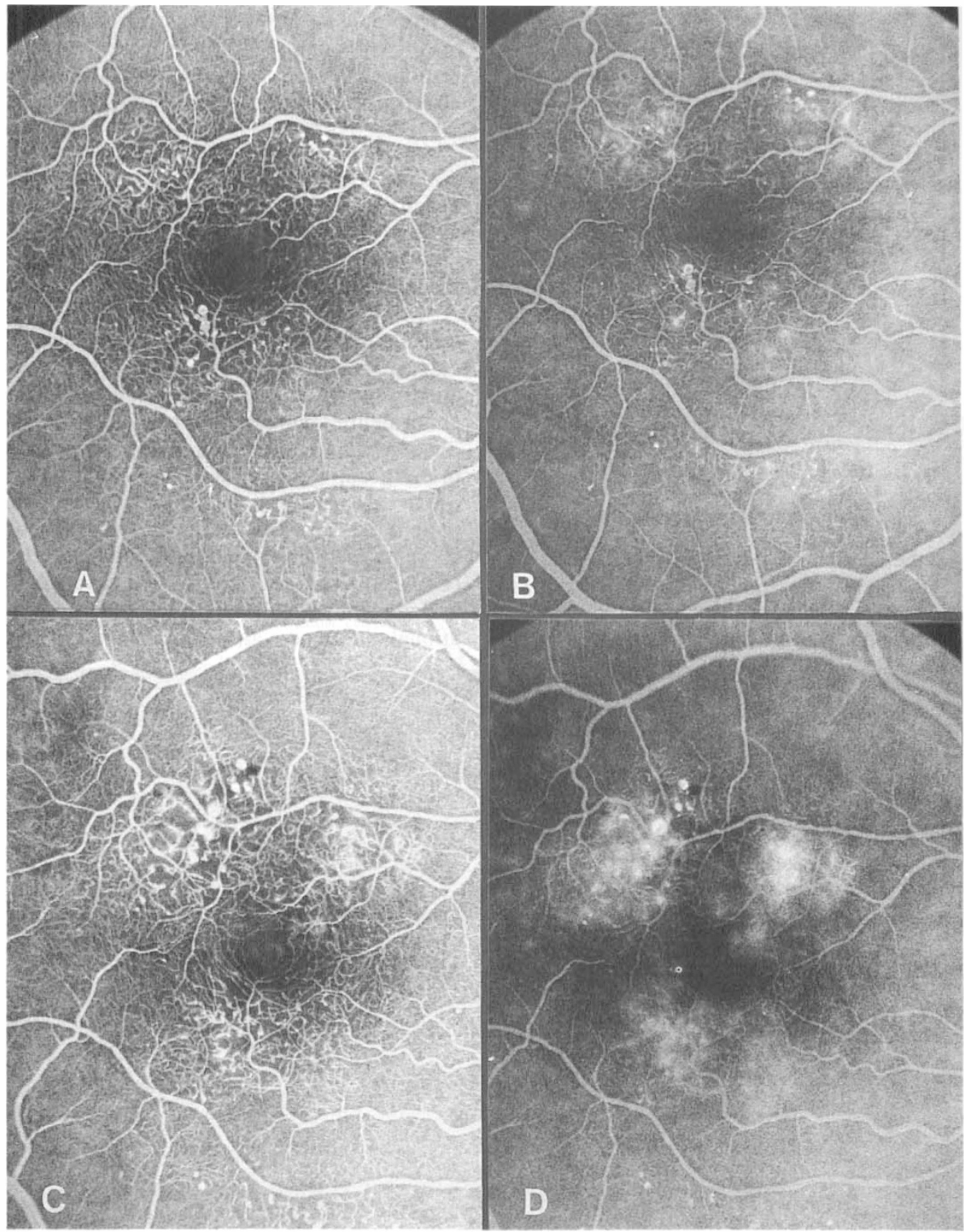

Fig. 3a. Venous-phase angiogram right posterior fundus Case 7. The macular microvasculature is grossly dilated and displays multiple microaneurysms of varying size. Small foci of capillary nonperfusion are evident.

Fig. 3b. Late phase angiogram of fundus shown Fig. 3a. Many dilated channels and microaneurysms stain and leak fluorescein into the nearby retina.

Fig. 3c. Venous-phase angiogram of fundus shown Fig. 3a, taken 37 months later. There is extension and intensification of retinopathy with capillary remodelling and appearance and disappearance of microaneurysms. The area of nonperfused retina has increased.

Fig. 3d. Late phase angiogram of fundus shown Fig. 3c. Dye leakage has increased compared with Fig. $3 b$. 


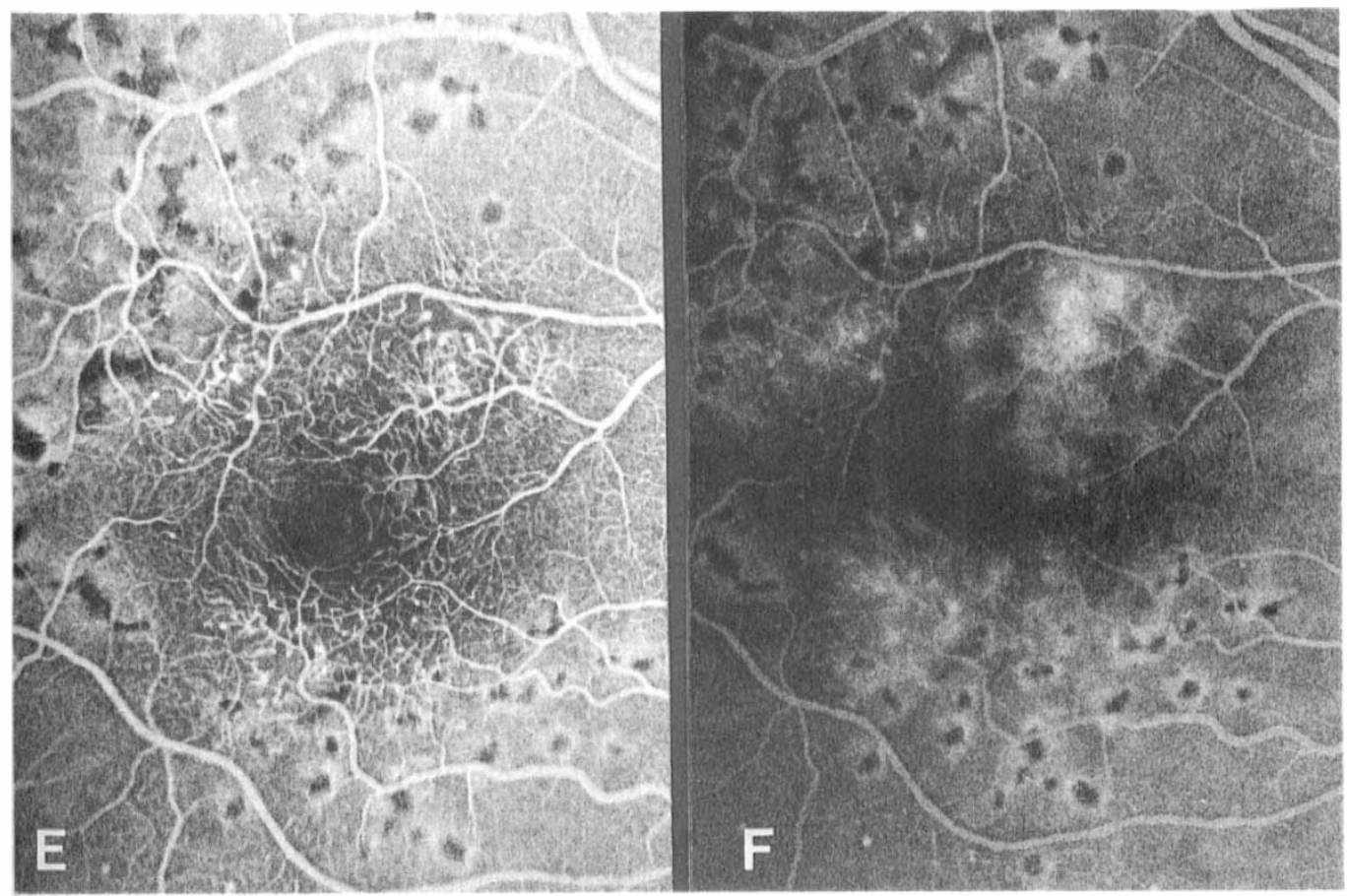

Fig. 3e. Venous phase angiogram following laser photocoagulation to fundus, shown above, 2 months after angiograms Figs. $3 c$ and d. Some defective capillaries are occluded and others reduced in calibre. Microaneurysms are reduced in number.

Fig. 3f. Late phase angiogram, fundus shown Fig. 3e. Dye leakage is reduced except at one untreated area superonasal to foveola. This was subsequently treated.

abnormality may have been a contributory factor.

\section{Grade 4 Retinopathy}

Four eyes demonstrated widespread disorganisation of the retinal microvasculature with extensive inner retinal ischaemia. Nonperfused retina was in excess of four disc areas, and one eye in this group developed preretinal neovascularisation and vitreous haemorrhage (Fig. 5). Two eyes with ischaemic maculopathy had visions of $6 / 60$ and $3 / 60$; however, two eyes with retinal ischaemia eccentric to the fovea retained vision of $6 / 6$ and $6 / 12$.

Two patients in this group were diabetic and documented as having early background diabetic retinopathy prior to radiotherapy (Cases 3 and 12). The development of extensive ischaemic retinopathy in each case after radiotherapy reflects the combined microvascular insult of the two disease processes. The effects were particularly severe in case 12

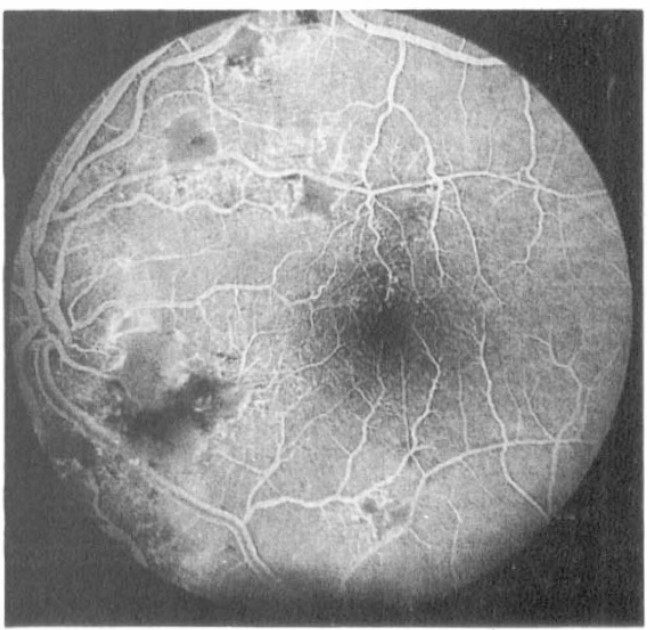

Fig. 4a. Mid-venous phase angiogram left posterior fundus (Case 2). There is advanced radiational retinopathy with focal areas of retinal nonperfusion, dilated and incompetent capillaries, and intraretinal haemorrhage. 


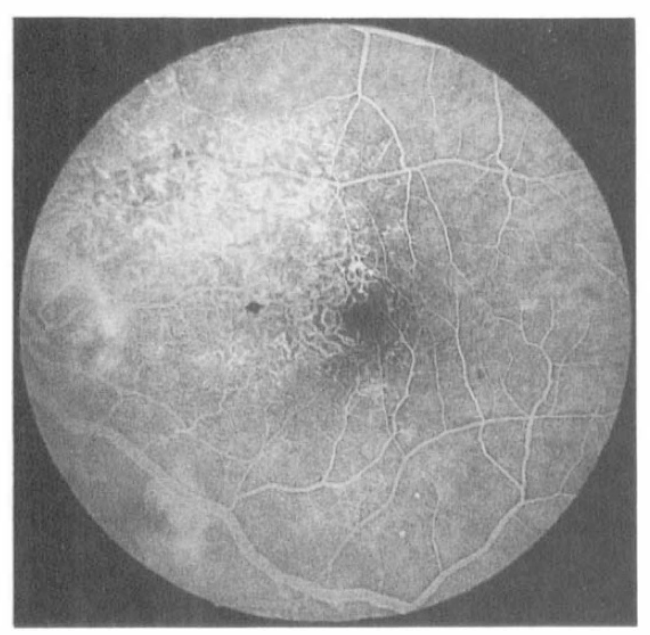

Fig. 4b. Venous phase angiogram fundus shown Fig. 4a, 18 months later. There is some reperfusion of ischaemic retina and development of incompetent telangiectatic-like channel over much of the nasal and superior macula.

where radiotherapy for a left lacrimal sac carcinoma resulted in severe ischaemia of the posterior retina at nine months and rubeosis iridis within twelve months of treatment.

\section{Sequential study of radiation retinopathy}

All nine patients (14 eyes) followed sequentially in this study demonstrated intensification and extension of retinopathy. No patient demonstrated any reversal of pathology or improvement in retinal microvascular competence, although attempts to recanalise nonperfused capillary beds were occasionally observed (Fig. 4). The progression of microvascular pathology varied in degree and extent (Table II), although the rate of change was typically slow, and in this series only one patient showed sufficient deterioration in the capillary bed to be regraded (Case 7, Fig. 3).

Over the period of observation all patients showed additional capillary closure and a net increase in the number of microaneurysms. In some eyes there was clear evidence of microaneurysm thrombosis and atrophy. All patients in groups 2 to 4 showed more microvascular incompetence with time as judged by the intensification of macular fluorescence in late phase angiograms. In one patient (Case 7) it was possible to quantify some of the retinal vascular changes and estimate the area of microvascular non-perfusion using image analysis of high-quality angiograms. Over a period of three years this patient demonstrated a $50 \%$ nett increase in the number of microaneurysms and a $70 \%$ nett increase in the area of non-perfused retina in spite of a considerable turnover in the number of microaneurysms, and abortive attempts at revascularisation of ischaemic retina (Fig. 3a and $3 \mathrm{c}$ ).

Three eyes followed in this study suffered loss of central vision concomitant with advancement of retinopathy, intraretinal fluid accumulation and macular ischaemia.

\section{Treatment}

Two patients in the present study received argon (green) laser photocoagulation for severe or advancing maculopathy associated with deterioration of vision. Focal laser photocoagulation was applied to areas of deformed and incompetent capillaries and regions of non-perfused retina (Fig. $3 \mathrm{e}, \mathrm{f}$ ). Both patients showed improvement in visual acuity (Case 7, 6/18 to 6/9) (Case 10, 6/36 to 6/12-2) within two to three months of therapy, and improvement was maintained at one year post treatment in each case.

Post-treatment angiography revealed that some deformed and telangiectatic vessels adjacent to photocoagulation burns collapsed



Fig. 5. Late venous phase angiogram of inferonasal fundus (case 15). There are multiple microaneurysms, extensive inner retinal ischaemia and a hyperfluorescent preretinal neovascular membrane. 
and failed to perfuse with dye. Other dilated capillaries were dramatically reduced in calibre, and demonstrated increased competence to fluorescein. Some microaneurysms either decreased in size or disappeared, and in some instances became less permeable to dye (Fig. 3e, f). Photocoagulation did not result in any observable reperfusion of ischaemic retina. One patient with widespread retinal ischaemia, preretinal neovascularisation and vitreous haemorrhage was advised to have laser therapy but declined treatment.

\section{Discussion}

Radiation retinopathy subsequent to both brachytherapy and teletherapy has been the subject of fluorescein angiographic investigation by several workers. The early studies of Chee, ${ }^{1}$ Gass $^{2}$ and Hayreh ${ }^{3}$ demonstrated that all components of the retinal microvasculature could be affected, and that angiography was useful in identifying microvascular pathology and demonstrating changes in vascular perfusion and competence. Subsequent angiographic investigations have also confirmed that the outer retina and choroidal circulation could be implicated in the disease process, and that photocoagulation could limit some of the sight-threatening complications of end-stage retinopathy. ${ }^{4,5,6,7,16,17}$

The progressive nature of radiation retinopathy has been emphasised; however, the natural course of clinical radiation retinopathy is still poorly understood, largely due to the difficulties encountered in mounting longitudinal studies in patients who are often ill, who have a poor life expectancy, and who occasionally develop corneal and lens opacities limiting observation of the ocular fundus. $^{18}$ The long latent period between irradiation and development of retinopathy and the typically slow progression of microvascular changes also make sequential analysis of the vasculopathy difficult and hinder prospective investigations. Furthermore, as early microvascular pathology is not usually associated with significant loss of vision, patients with early retinal changes are unlikely to be identified unless screening procedures are instituted.

The retinal microvascular alterations induced by ionizing radiation are observed most accurately in patients undergoing radiotherapy for extraocular tumours and orbital disease, e.g. lymphoma and Grave's Disease, as radiotherapy of intraocular tumours introduces not only the impact of ionising radiation on the retinal vessels but also the secondary effects of the tumour and its postradiational necrotic products on the retinal neuropile and microvasculature. Brachytherapy for intraocular tumours also causes local obliteration of the choroidal circulation ${ }^{3,8,9,10}$ and profound alterations in the nearby retinal pigment epithelium ${ }^{3,9}$ which may influence the form and function of the nearby retinal microvasculature.

This study was successful in identifying early radiation retinopathy and monitoring the development of microvascular changes as a large number of patients receiving substantial ocular radiation were screened and a significant proportion of these had early pathology. Furthermore, some patients with bilateral retinopathy had advanced disease in one eye but only early or incipient changes in the fellow eye which were particularly suitable for angiographic analysis. Also, in most patients radiotherapy was successful in containing the primary malignant disease process thereby facilitating long term observation.

The earliest identifiable changes of radiation retinopathy (Grade 1) were focal capillary closure and irregular dilatation of the neighbouring microvasculature. The affected vessels were typically competent in early disease although their walls often stained with dye in late angiography. Retinal oedema was not a feature and visual functions were not measurably affected. With time, further localised collapse of the capillary bed occurred, with development of additional dilated irregular capillaries. These dilated and telangiectatic-like vessels probably represent capillary collaterals which divert blood from defunct microvascular units.

The precise aetiology of capillary closure is unknown, however, it is likely that ionizing radiation directly affects vascular endothelial cell viability or its potential to replicate, and the subsequent failure of the capillary endothelium precipitates platelet deposition, capillary thrombosis and focal atrophy of the retinal microvasculature..$^{3,5,7,14}$ Microaneu- 
rysms were also a feature of early retinopathy and typically formed in dilated capillaries which bordered perfused and non-perfused capillary beds. Their formation may be due to the effects of a local increase in intra-luminal pressure on channels which have been structurally compromised by the loss of either endothelial cells or pericytes.

As early radiation retinopathy advanced, a significant part of the capillary bed, usually including the macula, became involved (Grade 2). Dilated, tortuous and fusiform capillaries were the principal angiographic feature and microvascular incompetence occurred as judged by fluorescein leakage. Despite the presence of dye leakage, intraretinal accumulation of fluid was often not pronounced and central visual functions were frequently surprisingly good despite involvement of the macular and perifoveolar circulations. The absence of clinically discernible intraretinal fluid accumulation is probably a measure of the efficiency of neighbouring intact capillaries and local retinal pigment epithelium in dehydrating the affected retina.

Further progression of retinopathy is characterised by the closure of additional capillary beds, formation of intraretinal microvascular abnormalities ${ }^{18}$ and the development of additional microaneurysms (Grade 3 ). A quantitative analysis of such effects in one patient revealed that the number of microaneurysms doubled in three years and that the area of capillary-free retina also increased by a factor of about two. More generalised microvascular incompetence was associated with clinically evident retinal oedema, and where the foveola was implicated, visual functions declined sharply.

End stage radiation retinopathy (Grade 4) is characterised by generalised microvascular disorganisation, inner retinal ischaemia and capillary incompetence often leading to cystoid macular oedema. The degree of inner retinal ischaemia in Grade 4 eyes may be sufficient to promote preretinal neovascularisation. Other authors have also described papillary neovascularisation, ${ }^{6,18,19}$ vitreous haemorrhage, ${ }^{16,19}$ retinal detachment, rubeosis iridis and secondary glaucoma in such eyes which usually have received high doses of ocular radiation. ${ }^{16,19}$
Angiographic evidence of choroidal closure or atrophy has mostly been described in patients having radioactive plaque therapy for choroidal melanomas and retinoblastomas $^{7,9,10}$. The only angiographic changes in the choroid following teletherapy were noted by Thompson et al. ${ }^{6}$ who described delayed choroidal filling in patients receiving radiation for nasopharyngeal tumours. Choroidal vascular stasis, however, was only encountered in hypertensive patients and was not attributed specifically to radiation damage. The present study has demonstrated angiographically that the choroidal circulation can be compromised by gratuitous external beam irradiation of the eye, and that subretinal neovascularisation may occur in association with radiational retinopathy. Whether any causal relationship exists between choroidal neovascularisation and radiotherapy is not known; however, degenerative changes induced in the retinal pigment epithelium and outer retina by radiation may encourage the development of subretinal neovascularisation particularly in ageing patients with evidence of drusen formation.

This study has confirmed that laser photocoagulation can have a beneficial effect on radiation-induced maculopathy and suggests that patients who benefit most from photocoagulation are those with early to moderate macular oedema, without cystoid degenerative changes and who retain moderate visual functions, i.e. $6 / 24$ or better. Kinyoun et al. ${ }^{16}$ and others ${ }^{6,17,19}$ have noted that laser photocoagulation not only has a positive effect on radiational maculopathy but also serves to contain or eliminate preretinal and papillary neovascularisation, thereby reducing the incidence of vitreous haemorrhage and retinal detachment.

The mechanism whereby laser photocoagulation improves retinal vascular competence is not known, although this study and others confirm that judicious photocoagulation effectively occludes and ablates some incompetent capillaries and microaneurysms. This study also demonstrates that laser photocoagulation indirectly reduces the calibre of dilated and deformed capillaries, possibly by diminishing cell density in the outer retina in the vicinity of the affected microvasculature. ${ }^{20}$ 
Theoretically the depopulated and attenuated retina will have lower metabolic requirements and may permit better oxygenation of the inner retina and its vascular cells from the choroidal circulation. ${ }^{21,22}$ Photocoagulation burns may also create defects in the retinal pigment epithelial layer, producing conduits which facilitate the drainage of excess retinal fluid into the choroidal circulation. ${ }^{23}$ Alternatively, it could be argued that, following laser photocoagulation, the rejuvenated retinal pigment epithelium has more effective pumping properties and is consequently able to dehydrate the oedematous retina. Nevertheless, irrespective of the mechanism whereby laser photocoagulation improves microvascular function in radiational retinopathy it is clearly an important therapeutic tool, particularly in early maculopathy and vasoproliferative disease. Accordingly, we would suggest that patients receiving in excess of $3,000 \mathrm{cGy}$ to the eye should be regularly reviewed and that patients receiving greater than $5,000 \mathrm{cGy}$ to the eye should be closely observed. Ophthalmologists should also liaise with radiotherapists carrying out cephalic radiation, particularly to patients with nasopharyngeal and paranasal sinus tumours, both to acquaint the radiotherapist regarding the likelihood of radiation retinopathy and to encourage where possible effective screening of the eye during treatment of these malignant tumours.

\section{References}

${ }^{1}$ Chee PHY: Radiation retinopathy. Am J Ophthalmol 1968, 66: 860-5.

${ }^{2}$ Gass JDM: A fluorescein angiographic study of macular dysfunction secondary to retinal vascular disease VI. X-ray irradiation, carotid artery occlusion, collagen vascular disease and vitritis. Arch Ophthalmol 1968, 80: 606-17.

${ }^{3}$ Hayreh SS: Post-radiation retinopathy: A fluorescence fundus angiographic study. $\mathrm{Br} \mathrm{J}$ Ophthalmol 1970, 54: 705-14.

${ }^{4}$ Bagan SM and Hollenhorst RW: Radiation retinopathy after irradiation of intracranial lesions. $\mathrm{Am}$ J Ophthalmol 1979, 88: 694-7.

${ }^{5}$ Brown GC, Shields JA, Sanborn G et al.: Radiation retinopathy. Ophthalmol 1982, 89: 1494-501.

${ }^{6}$ Thompson GM, Midgal CS, Whittle RJM: Radi- ation retinopathy following treatment of posterior nasal space carcinoma. Br J Ophthalmol 1983, 67: 609-14.

${ }^{7}$ Ehlers $\mathbf{N}$ and Kaae S: Changes in radiation treated retinoblastoma and radiation effects in the normal ocular fundus. Acta Ophthalmol 1987, Suppl 181, 65: 32-62.

${ }^{8}$ Lommatzsch P: Beta-irradiation of choroidal melanoma with $106 \mathrm{Ru} / 106 \mathrm{Rh}$ applicators. Arch Ophthalmol 1983, 101: 713-7.

${ }^{9}$ Lommatzsch PK, Ballin RE, Helm W: Fluorescein angiography in the follow-up study of choroidal melanoma after $106 \mathrm{Ru} / 106 \mathrm{Rh}$ plaque therapy. Retina 1987, 71: 148-155.

${ }^{10}$ Tarkkanen A and Laatikainen L: Fluorescein angiography in the long-term follow-up of choroidal melanoma after conservative treatment. Acta Ophthalmol 1985, 63: 73-9.

${ }^{11}$ Wara WM, Irvine AR, Neger RE et al.: Radiation retinopathy. Int J Radiat Oncol Biol Phys 1975, 5: $81-3$.

${ }^{12}$ Irvine AR, Alvarado JA, Wara WM et al.: Radiation retinopathy: an experimental model for the ischaemic-proliferative retinopathies. Trans $\mathrm{Am}$ Ophthalmol Soc 1981, 79: 103-20.

${ }^{13}$ Martin H and Reese AB: Treatment of bilateral retinoblastoma (retinal glioma) surgically and by irradiation. Arch Ophthalmol 1945, 33: 429-38.

${ }^{14}$ MacFaul PA and Bedford MA: Ocular complications after therapeutic irradiation. Br J Ophthalmol 1970, 54: 237-47.

${ }^{15}$ Noble KG and Kupersmith MJ: Retinal vascular remodelling in radiation retinopathy. $\mathrm{Br} \mathrm{J} \mathrm{Oph-}$ thalmol 1984, 68: 475-8.

${ }^{16}$ Kinyoun JL, Chittum ME, Wells CG: Photocoagulation treatment of rádiation retinopathy. $A m \mathrm{~J}$ Ophthalmol 1988, 105: 470-8.

${ }^{17}$ Chaudhuri PR, Austin DJ, Rosenthal AR: Treatment of radiation retinopathy. $\mathrm{Br} J$ Ophthalmol 1981, 65: 623-5.

${ }^{18}$ Amoaku WMK and Archer DB: Cephalic radiation and retinal vasculopathy. Eye 1990, 4: 195-203.

${ }^{19}$ Parsons JT, Fitzgerald CR, Hood CI et al.: The effects of irradiation of the eye and optic nerve. Int J Radiat Oncol Biol Phys 1983, 9: 609-22.

${ }^{20}$ Marmor MF: Clinical physiology of the retina. In: Principles and Practice of Ophthalmology. Eds: Peyman GA, Saunders DR, Goldberg MF. Philadelphia, WB Saunders Co 1980, 823-856.

${ }^{21}$ Wolbarsht ML and Landers MB: The rationale of photocoagulation therapy for proliferative diabetic retinopathy. A review and a model. Ophthalmic Surg 1980, 11: 235-45.

${ }^{22}$ Landers MB, Stefansson E, Wolbarsht ML: Panretinal photocoagulation and retinal oxygenation. Retina 1982, 2: 167-75.

${ }^{23}$ Golbaum MH: Photocoagulation: Theory and Practice. In: Principles and Practice of Ophthalmology Vol II. Eds: Peyman GA, Saunders DR and Goldberg MF. Philadelphia. Saunders WB Co 1980, 1098-1122. 